\title{
Impact of Language Ego, the Native Language Effect on Oral English Learning of High School Students
}

\author{
Guo Xiashi ${ }^{1} \&$ Yuewu Lin ${ }^{1}$ \\ ${ }^{1}$ Foreign Languages College, Jiangxi Normal University, China \\ Correspondence: Yuewu Lin, Foreign Languages College, Jiangxi Normal University, Yaohu Campus, 99 Ziyang road, \\ Nanchang, Jiangxi, 330022, China. E-mail: 1024610498@qq.com
}

Received: April 21, 2021 Accepted: May 4, 2020 Online Published: May 6, 2020

doi:10.11114/ijecs.v3i1.4841

URL: https://doi.org/10.11114/ijecs.v3i1.4841

\begin{abstract}
Language transfer, especially the native language effect on the process of second language acquisition, has always been a hot issue of various linguists. Language transfer is inevitable in the process of second language acquisition, which can be divided into positive transfer and negative transfer. The positive transfer will promote the foreign language learning while negative transfer of mother tongue will hinder the second language learning. In English learning, compared with reading and writing, oral English learning is more important and more complex. Chinese high school students are often disturbed by negative effect of their mother tongue in oral English communication. In China, experts and scholars have done a lot of researches on the negative native language effect in English learning, but most of the researches focus on writing and translation skills, while few of them emphasize on listening and speaking skills.

At present, English teaching is undergoing a profound reform, and English teachers and learners are paying an increasing number of attention to the study of spoken English. In order to fill the gap and correctly understand the influences of oral English acquisition of high school students, through the analysis of the principle of native language effect, this paper finds that the vocabulary, grammar, pronunciation and pragmatics of mother tongue all have negative transfer to foreign language learning. What' s more, language ego, as an important part of affective principles, has a profound impact on the process of oral English learning. There is a strong and negative correlation between language ego and oral English learning to some extent. The less students' language ego is, the more oral English output students will produce.
\end{abstract}

Keywords: language transfer, language ego, oral English

\section{Introduction}

Language transfer refers to the tendency of a person to transfer knowledge acquired in one language to another language. Students who are going to learn a foreign language have already mastered their mother tongue. In the process of second language acquisition, especially the competence of oral production, native language will play a vital role in it. In China, English needs to be learned in the environment of mother tongue, so mother tongue is so crucial that it will affect the form of English communication and the formation of English sentences. However, language transfer is composed of active transfer and negative transfer. Owing to the negative effect of native language, most high school students are in a state of rather low oral output. Moreover, language ego, as one of the affective principles, also attributes to the oral English production. These two factors have something to do with the serious phenomenon of "the dumb English" in China.

With reference to the researches of language transfer, many linguists have made their theoretical contributions, such as Odin(1989), Gass and Selinker(2001), Ellis (1994), Lado(1957) and so on. Language transfer has been a major problem in Applied Linguistics, Second Language Acquisition and Language Teaching for at least 100 years. Ellis (1994) mentions that language transfer errors in second language acquisition are caused by negative transfer of mother tongue. Without doubts, mother tongue has a negative influence on learners' second language acquisition, having become the focus of theoretical and empirical studies at home and abroad. Nonetheless, scholars pay more attention to the reading and writing of the target language rather than speaking.

In 2017, the new course syllable for English claims that senior high school students should be able to express themselves in oral English and conduct interpersonal communication efficiently and appropriately. On the basis of the related study achievements, together with language ego, this paper studies the negative influence of native language on the oral English 
of senior high school students, aiming to provide reference and experience for future researches on negative effect of native language and theoretical basis and potential methods for English learner.

\section{Literature Review}

\subsection{Definition of the Native Language Effect}

Native language effect, or language transfer, stems from the concept of psychology, which means that the original knowledge and skills of learners will have an impact on the new knowledge and skills during the learning process.

As for Brown (2001), the native language of learners will be a highly significant system on which learners will rely to predict the target language system. While that native system will exercise both facilitating and interfering effects on the production and comprehension of the new language, the interfering effects are likely to be the most salient.

Lado (1957) points out that when learning a second language, learners will rely on the mother tongue instinctively. Learners will transfer some rules and habits of the native language to the second language acquisition. Language transfer can be divided into positive transfer and negative transfer. When some features of the mother tongue and the target language are similar or consistent, positive transfer will occur, thus promoting the second language acquisition.

Dechert (1989) argues that while there are some differences between the mother tongue and the target language, negative transfer will occur and hinder foreign language acquisition. Language transfer is inevitable, existing in every aspect of foreign language learning.

Ellis (1965) defined "language transfer" as an assumption that the learning target A will affect the acquisition of target B, and affirmed that this is the most significant notion in educational theories and application.

Accoding to James (1980), if we replace target A with the first language and target B with the second language, and thus the definition of language transfer formed.

From the above statements, although many experts and scholars have reached different conclusions on the phenomenon of language transfer, it has been proved that language transfer exists in second language acquisition, both positive and negative. This paper studies the negative transfer of the native language.

\subsection{The Definition of Language Ego}

According to Brown (2001), The language ego principle can be summarized in a well-recognized claim: As human beings learn to use a second language, they also develop a new model of thinking, feeling, and acting---a second identity. The new "language ego," intertwined with the second language, can easily create within the learner a sense of fragility, a defensiveness, and a raising of inhibitions.

It can also be called the "warm fuzzy" principle. When learning a second language, we often feel silly and humiliated to speak like a infant. Dale E. Hinchey (2004) believed that the formation of language ego must go through five stages: form, feeling, perception, concept and consciousness. Since we have acquired a good mother tone, we can express ourselves frequently and appropriately in native language. It is of difficulty for us to have an excellent face to face communication for the lack of words and structures. Consequently, learners feel fragile when they learn the second language, which needs a lot of supports and encouragements.

\section{Different Types of Negative Transfer in Oral English}

According to different language categories, negative transfer can be further divided into various subtypes. Some representative ones will be analyzed and discussed in the following paragraphs.

\subsection{Vocabulary}

Vocabulary is the basis of language and plays an important role in daily communication and knowledge acquisition, which is easily influenced by the mother tongue. Some words with similar meaning between Chinese and English, which makes learners believe there is a one-to-one relationship between each Chinese and English word. In fact, there are still great differences between them.

Williams(1983) mentiones that words have denotative and connotative meanings. Denotative meaning indicates that words are related to events and objects in the world. The connotative meaning means that language learners always choose different words according to their emotions, which will affect the understanding of listeners. Meanwhile, the semantic relationship of words can be divided into syntagmatic relation and paradigmatic relation. Different words can be obtained in different language situations.

\subsubsection{Nouns}

Nouns refer to people, things, ideas or events, etc. Nouns usually serve as the subject, object and predicative of a sentence in both Chinese and English languages. But it is inappropriate to assume that the nouns in both languages are identical. 
In English, nouns can be divided into countable nouns and uncountable nouns. Only countable nouns have singular and plural forms. However, in China speakers often use nouns in different ways. Some nouns are uncountable in English but can be used as countable nouns in Chinese. For example, the words "scenery", "news" and "suggestion" are uncountable nouns in English, while in Chinese they are countable nouns. Therefore, it is easy for English learners to make mistakes. Since English is a labeling language, the singular and plural forms of English nouns are realized by adding the indefinite article "a" or "an" and the suffix "-s" or "-es". Compared with English, Chinese is a non-labeling language. There is no difference between the plural and singular forms of Chinese nouns. A large number of errors caused by negative transfer due to students' confusion in this aspect.

\subsubsection{Verbs}

The verb, from the Latin word "verbum," is often used to convey a variety of actions. It is the main part of the sentence. Almost every complete sentence has at least one verb, which is extremely important for the conveying of the message and for communication. The verb system of English is more complicated than that of Chinese.

It is indisputable that Chinese students are often confused and make many mistakes when using English verbs. For example, verbs can be divided into transitive verbs and intransitive verbs according to whether they can carry objects directly, in both English and Chinese. But they are not completely equivalent. Some transitive verbs in Chinese may become intransitive verbs in English. For example, in the sentence "They are waiting for cars", "wait" is an intransitive verb in English, while "deng" in Chinese is transitive. In contrast to English, objects that appear after transitive verbs can also be deleted in Chinese. In English, except for the basic form, other verb forms focus more on verbs with non-predicate forms that can be further divided into infinitives, present and past participles, whereas only one verb can act as a predicate. Chinese students may be confused because there are no such inflections in Chinese verbs. Consequently, a lot of grammatical errors may occur in the spoken English of high school students.

\subsubsection{Preposition}

Prepositions are grammatically unique word categories whose core function is to express typical spatial relationships (e.g., in, under, toward) or to mark different syntactic functions and semantic roles (e.g., of, for)". There are prepositions in both English and Chinese. Compared with Chinese, English prepositions are more complicated, and frequently used. It is estimated that there are thirsty prepositions in the Chinese language, but in English there are two hundred and eight six(Liang Shuneng, 1993). Baron claims that "Mandarin has no special class of words corresponding prepositions in English"(Li Zhen, 2004).

It is said that English is a language composed of prepositions. Chinese students think some prepositions are completely unnecessary and can be omitted. For example, Chinese learners may think "go park" is correct, from which the negative influence of Chinese can be fairly well reflected. Multiple and inappropriate vocabulary sets are two common mistakes Chinese students made in prepositions. The preposition "zai" in Chinese has the same meaning as four different English prepositions "in", "a", "to" and "on". Therefore, it is difficult for Chinese learners to identify the two phrases "on the north 'and in the north". Prepositions with identical meaning while different usage confuse students a lot especially in oral English, for students cannot distinguish them within a limited time.

\subsubsection{Article}

First and foremost, there is no article in Chinese. The article itself has no definition and no lexical meaning. The article must appear before the noun it modifies. In other words, articles are attributives of nouns and are usually used to indicate the quantity and quality of nouns. Articles in English can be divided into three types, including definite articles, zero articles and indefinite articles. The definite article "the" refers to something mentioned or specified earlier. The indefinite article "a, an" indicates that the noun it modifies is not specific and is easily recognizable to the listener.

And zero article means no article is used. It is usually used with plural nouns and uncountable nouns. In Chinese, words like "zhe" and "na" and "yi" are often added before nouns instead of articles. The clear difference between Chinese and English makes students encounter great problems in article learning. It is difficult for Chinese students to understand and accept the rules of articles. They do not know when to use articles and what kind of articles should be added before nouns in different contexts.

\subsection{Grammar}

English grammar are rules that play an organizational role in language. A complete language system cannot be separated from the restriction of grammar rules. However, there are also many differences in grammar between Chinese and English. Chinese grammar is more concerned with coordinate relation rather than affiliation. However, English is characterized by the use of a large number of inflected and syntactic languages to express its grammatical relationships. In this section, it will focus on on these three parts: ellipsis, word order and tense. 


\subsubsection{Ellipsis}

English is a right-branching language while Chinese is a left-branching language. The subordinate relation of English means that the ellipsis of any part of an English sentence is different in meaning. Compared with English, Chinese is a paratactic language without any mark, and the logical relationship between phrases and sentences is expressed by the use of semantics. Therefore, almost any element in a sentence can be omitted as long as the context of the conversation and the meaning of what people are talking about are obvious. The western grammar is rigid and has no elasticity; while Chinese grammar is soft and full of flexibility.

Take subject as an example. In Chinese the deletion of subject happens usually, which can express the relevant grammatical meaning without any misunderstanding. It is probably one of the most distinctive features of Chinese sentences. However, subjects that get more attention in English cannot be removed at will. Because it is the basic element of an English sentence. The subject is closely related to other components of the sentence, such as the predicate and the object. In addition, the omission of object, be or auxiliary verbs, is also very different between English and Chinese.

\subsubsection{Word Order}

Word order refers to the order of words in a sentence, which can represent the internal relationship between words. The basic word orders of most human languages are VSO, SVO or SOV. The basic word order of English is relatively fixed: SVO. While Chinese sentences have two orders: SVO and SOV, its basic order is decided by pragmatic and semantic not the grammar. Dulay, Burt and Krashen(1982) point out that the word order errors are usually caused by the learners when they learn the target language they interpret the native language word by word. Word order reflects the thinking mode of language users. Because Chinese and English speakers have very different ways of thinking, they will use different word order to explain the same thing.

English is the sentence-centered language, and a sentence is a complete grammar unit. A subject-prominent grammar, and subject-predicate relation play the leading role in explaining the basic sentence structure; as for the division of Chinese sentence, it is not clear like that and can be called topic-prominent language. Relationship of theme-rhyme could account for basic sentence structure.

Chinese people's way of thinking tends to focus on how they feel about things, so Chinese sentences tend to emphasize logical order. The causality and priority order of elements in Chinese sentences usually directly reflect the temporal structure in real life. However, English speaking countries do not pay much attention to the correspondence between time series and word order. Word order in English can be arranged differently depending on the intonation of the speaker and the style and intention to be expressed. Therefore, the structure of English sentences has more flexibility. Thus, it is not difficult for the Chinese learners to understand English sentence in the way of understanding the softness of Chinese, and make out ungrammatical English sentences.

\subsubsection{Tense}

Comrie(1985:176) regarded tense as "a grammaticalized expression of location in time" and Whaley(1997:203) defined tense as "a grammatical expression of the relationship between two points of time." English is an inflectional language, and the change of tenses depends on the change of verbs. Tenses can indicate whether an action or state occurred in the past, present or future by inflections or morphemes of auxiliary verbs. It can be further divided into 16 subtypes, such as past tense, perfect tense, present tense, etc. However, there is a different way to show the change of tense in Chinese from English, which has become one of the most common mistakes Chinese students made in learning English, not only in the early stage of learning but also in the daily use of English after students have learned English for many years. Chinese is sometimes regarded as a physique language while English seems to be a temporal language.

In other words, Chinese pay more attention to whether the action has been completed or not. In Chinese, the morpheme "le" is often used to indicate an action that has been completed, which can take place in the future or in the past. To be precise, the perfect form in Chinese has nothing to do with tense. We just use some words of time, such as "zuo tian" "jin tian" "ming tian" to describe different events happening at different time.

Compared with Chinese, English tense is expressed by the inflection of verbs, adverbs or prepositional phrases. In other words, Chinese tense mainly rely on vocabulary instead of grammatical twists and turns. However, tense in English usually focuses on the form of grammatical functions, especially the change of verbs. Thus, because of aspect, voice and modality, parts of the students have no ideas about how to choose the appropriate forms of verbs in some certain language contexts. Under this situation, some of them are pretty much confused about the basic meanings of tense. Therefore, when taking exercises, they often find themselves difficult to express what they want to express properly or smoothly in oral English. As time goes by, they are even afraid to speak English. 


\subsection{Pronunciation}

Chinese is a language of the trinity of sound, form and meaning, which is embodied in the relation between sound and meaning, presenting the property of nonlinear structure. English, on the other hand, is a polysyllabic language, a linear combination. From the perspective of phonetics, Chinese is a typical tonal language with four tones: "ping, shang, qu and ru". Tones use different tonal values to distinguish syllables and word meanings, which are not found in English. And the English phonetic system also has intonation and stress that Chinese does not.

Therefore, English is also called "intonation language". When English words are formed into sentences, intonation is generated at the same time. For example, the sentence: I like apples. Declarative and referential intonations reflect the difference in speaker's tone or even attitude. In view of the differences between Chinese and English in this aspect, it has brought some troubles to high school students learning English pronunciation.

Secondly, in terms of vowels and consonants, Chinese and English have some similar sounds, which enables students to be confused about the English pronunciation. For instance, it is possible for Chinese students pronounce "visit" as "wisit". Besides, "thanks" and "sanks" are easily confused, on account of $/ \theta /$ and $/ \mathrm{s} /$ are extremely alike except for the place of articulation. However, $/ \theta /$ does not exist in Chinese, so high school students are likely to misunderstand the useage between them. Consequently, Chinglish pronunciation occurs. Thirdly, in view of word and sentence stress, most students are confronted with some acquisition difficulties. The rhythm of Chinese pays attention to the collocation of tones, which is also related to prosody; while in English, stress and unstressed syllables are dominant. The English phonetic system is generally stressed, supplemented by unstressed sounds, and they occur alternately. In the pronunciation of English sentences, sentences with less unstressed syllables will be read more slowly, on the contrary, sentences with more stressed syllables will be read more quickly. Therefore, students with mother tongue of Chinese will encounter great difficulties in rhythm, and will be accustomed to pronouncing each syllable of English in the same time as pronounce Chinese words, thus losing the inherent charm of English. Finally, about liaison, in English sentences, if the first word ends with a consonant and the next word begins with a vowel, the liaison and reduction occur. However, in Chinese, students have been accustomed to the pronunciation method of clear articulation and a mellow and full tune, so they may ignore the English liaison and reduction.

Owing to the differences in these four aspects, it is easy for students to transfer their Chinese pronunciation patterns to English pronunciation, causing negative $\theta$ effects.

\subsection{Pragmatic Errors}

Pragmatics studies the application of language in practice, focusing on the relationship between sentences and the relevant context. Pragmatics includes speech act theory, conversational implicature, interactive conversation and other aspects of linguistic behavior such as philosophy, sociology and linguistics.

Since the meaning of a language depends on the context in which it is communicated, such as manner, place, and time, pragmatics shows the ability of listeners and speakers to overcome obvious ambiguities. Kramsch (1998) states that the language transfer of pragmatics stems from the differences of living environment between westerners and easterners. That is to say, cultural differences lead to language transfer in pragmatics. As the carrier of culture, language is influenced by culture. When learning the target language, learners are also learning the culture of the target language.

There are many differences between Chinese and English because they are reflections of two different cultural systems. In Chinese, for example, the use of apology is more sophisticated than in English. Westerners often use "sorry" when they offend someone. In the eyes of many Chinese, some of them are completely unnecessary. These two different attitudes towards apologies are closely related to the differences in Chinese and English cultures. In China, if the elder offend the junior, they do not need to apologize because of their authority and reflection of power and influence. While westerners believe that all men are created equally, apologies are used to maintain order, and everyone should obey them. Therefore, anyone who offends others should apologize. As for expressions of gratitude, westerners always say "Thank you" to others, including their families, but Chinese people are not. Moreover, the phrase "Thank you" is different in Chinese and English. Westerners say "You are welcome" or "It is my pleasure" in response to "Thank you ", while Chinese people say "you are welcome" and "This is what I should do". Expressions about the same thing have different meanings in different cultures. Chinese high school students influenced by Chinese culture may habitually seek help from their mother tongue, preferring to think in Chinese rather than in English when trying to communicate with others in English.

To sum up, from the above analysis, it can be seen that language transfer has a profound impact on students' oral English communication at all levels-vocabulary, grammar, pronunciation and pragmatics. In order to minimize interfering transfer of mother tongue, students must be aware of the implicit and explicit knowledge in the field of language transfer, understand the differences between the two languages. 


\section{The Effect of Language Ego on Oral English}

When students are learning a second language, the development of their mother tongue is interrupted and is constantly modified and penetrated by the second language. Students in high school already have a good acquisition of their mother tongue, they can express themselves in Chinese accurately and fluently, and they have formed their language ego to some degree.

Due to the great differences between Chinese and English, such as vocabulary, pronunciation, grammar and pragmatics mentioned before, students' language ego may be damaged. For example, in terms of vocabulary, high school English curriculum standards issued in 2017 require high school students to master 3,000 words by the time they graduate. However, even for advanced students who have mastered all these words, they still have a big vocabulary barrier in the process of daily expression. In the process of second language cultivation, inhibition easily occurs when students encounter setbacks or threats, on account of the lack of the protection of sound native language. Ehrman (1993) describes how students behave in a second language class: most students are afraid to make a statement. Although they already have the ability to communicate in second language, no one actively answers questions. One student with excellent academic performance said, "Please do not ask me to answer questions, because I don't know anything. Let alone students with poor academic performance. Vocabulary is the basis of language learning. The lack of vocabulary will seriously destroy the language ego of high school students, which enables students to be afraid of speaking.

On the other hand, pronunciation is another important factor of dumb English for high school students. Owing to the significant different in Chinese and English in pronunciation, the students who find their pronunciation and native English pronunciation are quite different, even the native speaker cannot understand and their peers may laugh at their pronunciation, their language ego will be severely destroyed. At this time, they would like to resort to mother tone while decrease the output of oral English.

Just as some researches on language teaching show, in the second language learning, learners who are extroverted, confident, adventurous will be more successful in speaking and interpersonal communication. And confidence and risk taking are closed related with the language ego. Therefore, we can draw a conclusion that the higher the language ego of students is, the less possibilities for them to speak, because they are afraid of being laughed at. On the contrary, students with lower language ego care less about losing face in front of others and have higher tolerance for their own language mistakes, so they are more likely to speak in English in public. Li Ruifang (2004) wrote if we are not able to attain enough understandable input, then it is impossible for us to learn language well. Consequently, the negative impact of language ego occurs.

\section{The relationship between Language Ego and Native Language Transfer}

Children's language ego is relatively open, flexible and permeable, so it is easy to adapt and adjust when learning a new language. While learners are in adolescence, the development of ego is maturing and language ego is combined with stable protection mechanism. Due to the language ego of learners is relatively closed, it protects one's individual image, while the second language ego has not yet formed, so learners will be anxious about their language barrier and self-image threatened by peers in second language acquisition. In this way, negative emotions occur, such as inhibiting, which has a significant effect on their foreign language learning.

The affective filter hypothesis holds that affective factors are key conditions for language acquisition (Krashen 1982).The affective factors affecting English learning include learners' motivation, self-confidence and anxiety. Lack of motivation and self-confidence and too much anxiety will seriously hinder language input, resulting in learners' loss of the ability to actively acquire language input, thus hinders language acquisition. On the contrary, if learners have strong motivation, high self-confidence and low anxiety, they will weaken the emotional filter, which is conducive to language acquisition.

While language negative transfer is often influenced by emotional reasons. As one of the crucial affective factor, language ego has much to do with the negative language transfer. For one thing, when the language ego of high school students is too high, they are reluctant to take risks to practice spoken English, considering it foolish to speak as an infant, so negative language transfer happens. For another, if the language ego of students are moderate or low, they are willing to show and communicate with others in oral English. In this way, excellent emotional factors will decrease the impact of negative language transfer. There are negative correlation between language ego and negative language transfer.

\section{Conclusions}

\subsection{Major Findings}

Without doubt, language transfer has attracted an increasing attention and has been a controversial topic in the field of second language acquisition for the past decade. The researchers acknowledge that language transfer plays an important role in second language acquisition. They also point out that negative transfer is as important as positive transfer. If teachers and learners can deeply understand language negative transfer, they can clearly understand how the mother 
tongue affects second language acquisition and how to improve the quality of second language teaching in modern classrooms.

Through analysis, the linguistic and cultural differences between English and Chinese have been proved to be the main cause of oral English mistakes. Oral errors caused by negative transfer are distributed at all levels of English, vocabulary, grammar, pronunciation and pragmatics. Furthermore, non-verbal factors such as language ego should also be emphasized. High language ego will seriously damage the power and courage of students to express themselves in second language. Consequently, both verbal and non-verbal factors should be carefully considered.

\subsection{Implications}

The major findings above prove that negative transfer and language ego have much to do with the oral English learning of high school students. Consequently, the author puts forward some pedagogical implications for studnets and teachers to improve their spoken English ability.

\subsubsection{Implications for Students}

Firstly, students should attach more importance to negative transfer of mother tongue, establish correct consciousness on oral English and make full use of every chance to practice oral English.

Secondly, students should try their best to lower their awareness of their mother tongue, learning western culture step by step and thinking in the shoes of native speakers of second language. Famous linguists Dai Weidong and Shu Dingfang (1997) have found that it is unavoidable for learners to rely on the thinking habits and language structures of their mother tongue when studying a foreign language. Thus, what they can do is to accumulate more knowledge about native language habits. The more knowledge they have master, the more proficient they will be in language skills. Thus, students should increase the positive transfer but decrease the negative transfer.

Thirdly, learners must pay attention to distinguish the different social and cultural backgrounds and grammatical bases of the target language and the mother tongue, and do not apply Chinese expression habits and grammar rules directly to the learning of the target language, so as to overcome the influence of Chinese thinking and expression habits on English learning to some extent.

Last but not least, students should develop good daily English learning habits. For instance, use English-English dictionary and read more original works. Students need to accept the correct and idiomatic language input in language learning process so that they can gradually develop the ability to think in English. Only by inputting standard English language knowledge can correct and authentic English sentences and chapters be output to overcome the negative transfer of mother tongue.

\subsubsection{Implication for Teachers}

Meanwhile, the teaching ability of teachers should not be ignored.

First, Teachers should "overtly display a supportive attitude to your students". Teachers need to provide all the affective support that they possibly can, and help such students to understand that the confusion if not depression of developing that second self in the second culture is a normal and natural process (Brown, 2001).

Second, teachers must choose the appropriate corrective strategies. Teachers' error correction plays an important role in students' second language acquisition. It is not realistic to correct every error. For one thing, students' enthusiasm about SLA are discouraged by endless error correction. For another, students may be impressed by the wrong utterance instead of the right ones. They won't analyze carefully the reasons for their mistakes, which leads to a vicious circle of second language acquisition. Teacher should get a general idea of how to correct the mistakes made by students, in order to give a useful feedback to promote learners' understanding of the target language.

Next, teachers should change the role of traditional knowledge imparters to mediators (Fuerstein, 1991). At the same time, they need to overcome the negative impact of language ego and mother tone transfer by themselves, setting up an adorable example for students. On the basis of the correct understanding of students' language ego and transfer, teachers then assign appropriate tasks suitable for students to achieve.

Finally, abundant learning opportunities and experiences are inevitable for students, which provides ideal studying atmosphere, enhances learning confidence and develops effective learning strategie, such as watching lectures and enjoying excellent movies in English. Only in this way can students work out the negative effect of language transfer and language ego, and students' sense of second language will be develpoed and constructed positively. 


\section{Reference}

Brown, H. D. (2001). Teaching by Principles: An interactive Approach to Language Pedagogy. Foreign Language Teaching and Research Press, 22-23.

Comrie, Bernard. (1985). Tense. Cambridge: Cambridge University Press.

Dai, W. D., Shu, D. F. (1997). Some problems in contrastive analysis, error analysis and interlanguage research. Journal of Shanghai international studies university, 4, 32-40.

Dale, E. H. (2004). Language Ego Permeability and EgolessnesEB/OL. http://www.persoalweb. Smcvt.edu/dhinchey/ego.htm.

Dechert, H. W., \& Raupach M. (1989). Transfer in Language Production. Ablex Publishing Corporation, 311.

Ellis, H. (1965). The Transfer of Learning. New York: Macmillan.

Ellis, R. (1994). The Study of Second Language Acquisition. Oxford: Oxford University press, 212.

Erhman, M. E. (1993). Ego Boundaries Revisited: Toward a Model of Personality and Learning, Washington D.C.:Georgetown University Press, 330.

Gass, S. M., \& Selinker, L. (2001). Second Language Acquisition: An Introductory Course. Mahwah, New Jersey, London: Lawrence Erl: baum Associates Publishers.

James, C. (1980). Contrastive Analysis. London: Longman.

Kramsch, C. (1998). Language and Culture. London: Oxford University Press.

Krashen, S. D. (1982). Principles and Practice in Second Language Acquisition, oxford; Pergamon Press.

Lado, R. (1957). Linguistics Across Cultures. Ann Arbor: University of Michigan Press.

Li, R. F., \& Meng, L. X. (2004). The impact of grammatical metaphors on language input in second language learning. Foreign Language Teaching, 3, 79-80.

Li, Z. (2004). Analysis of oral English errors. Central China Normal University.

Lian, S. (1993). Comparative study of English and Chinese. Beijing: Higher education press, 50-54.

Odlin, T. (1989). Language Transfer, Cambridge: Cambridge University Press.

Whaley. (1997). Saving Language. London: Cambridge University Press, 203.

Williams, R. H. (1983). Keywords: A Vocabulary of Culture and Society. Oxford. Oxford University Press.

\section{Copyrights}

Copyright for this article is retained by the author(s), with first publication rights granted to the journal.

This is an open-access article distributed under the terms and conditions of the Creative Commons Attribution license (http://creativecommons.org/licenses/by/4.0/). 